\title{
Article \\ The idea of measuring the real induction in the machining gap filled with magnetic material
}

\author{
Michał Marczak ${ }^{1, *}$, Adrian Kopytowski ${ }^{1}$, Rafał Nowicki ${ }^{1}$, Grigor Stambolov ${ }^{2}$ \\ ${ }^{1}$ Warsaw University of Technology, Poland \\ Adrian Kopytowski M.Sc. Eng., adriankopytowski@wp.pl; \\ Rafał Nowicki M.Sc. Eng., rano@meil.pw.edu.pl; \\ ${ }^{2}$ Technical University of Sofia, Bulgaria \\ prof. Grigor Stambolov, gstamb@gmail.com; \\ * Correspondence: Michał Marczak Ph.D. Eng., mim@meil.pw.edu.pl
}

Received: 26.02.2019; Accepted: 12.06.2019

\begin{abstract}
The article presents the characteristics of the distribution of magnetic flux density inside the machining gap in the magnetic abrasive finishing (MAF). Based on the analysis of the magnetic field in the empty gap and the distribution of forces in the magnetic circuit, the concept of measuring the real value of magnetic induction in a flexible abrasive tool formed in an external magnetic field was proposed. An indirect way of determining the magnetic induction has been described, which has a significant influence on the force acting on abrasive grains in the process of magnetic abrasive finishing. The advantages and the problems of the applied approach as well as the measurement methodology based on the change in the attraction force of the magnetic field elements as a result of the change in the concentration of abrasive grains and the width of the machining gap are presented.
\end{abstract}

Keywords: magnetic circuit; magnetic abrasive finishing; ferromagnetic abrasive grains

\section{Basics of the magnetic-abrasive finishing process}

The use of a magnetic field as a binder enables the adaptation of the flexible abrasive tool to the work surface [1]. In the basic configuration (Fig. 1), the workpiece is located in an external magnetic field together with an abrasive tool in the form of ferromagnetic abrasive grains or a mixture of traditional abrasive grains and magnetic powder. In the case of solid ferromagnetic abrasive grains, the advantage of the process is their orientation in accordance with the magnetic field lines, which also occurs in the case of worn (blunt) abrasive grains. The machining is carried out after introducing additional work movement of the workpiece (rotational, reciprocating and progressive motion) or abrasive tool (magnetic head, e.g. rotary motion) [2]. Proper design of additional working movements allows achieving non-directional machining [3].
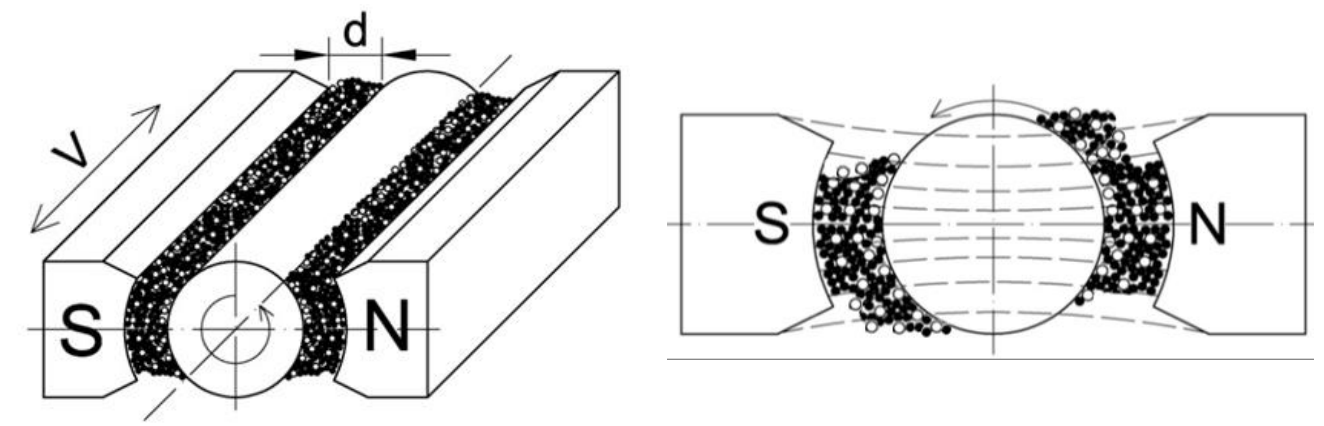

Fig. 1. One of magnetic finishing machining kinematic configuration

\section{Flexible abrasive tool}

The role of the tool is fulfilled by abrasive grains, which are bonded by a magnetic field. In the case of traditional abrasive machining, which is grinding [4], the binder has a number of features and properties that have a significant impact on the process, such as:

- number and size of pores (structure) - placement of machining products, reduction of the contact area with the workpiece, reduction of the tool weight; 
- holding force of the abrasive grains - affects the possibility of obtaining the effect of self-sharpening of the grinding wheel;

- coefficient of thermal conductivity - affects the amount of heat dissipated;

- coefficient of friction of the binder against the workpiece - affects the amount of heat released during the process;

- fragility - affects performance and work safety.

In the case of a magnetic abrasive machining (Fig. 2), the binder in the form of a magnetic field has the following features:

- does not wear out during the process - it is an external effect;

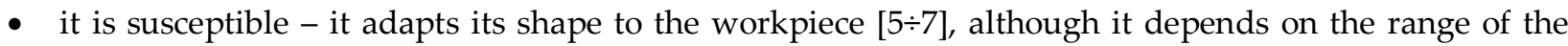
field's influence;

- can cause the temperature in the surface layer of the workpiece to rise, due to the occurrence of eddy currents, depending on the frequency of field changes;

- facilitates removal of processing products;

- does not generate friction during machining;

- affects abrasive grains with less force - depending on induction distribution in the machining gap;

- provides the conditions for the self-sharpening process - solid ferromagnetic abrasive grains are positioned with their longer axis along the field line $[8,9]$.
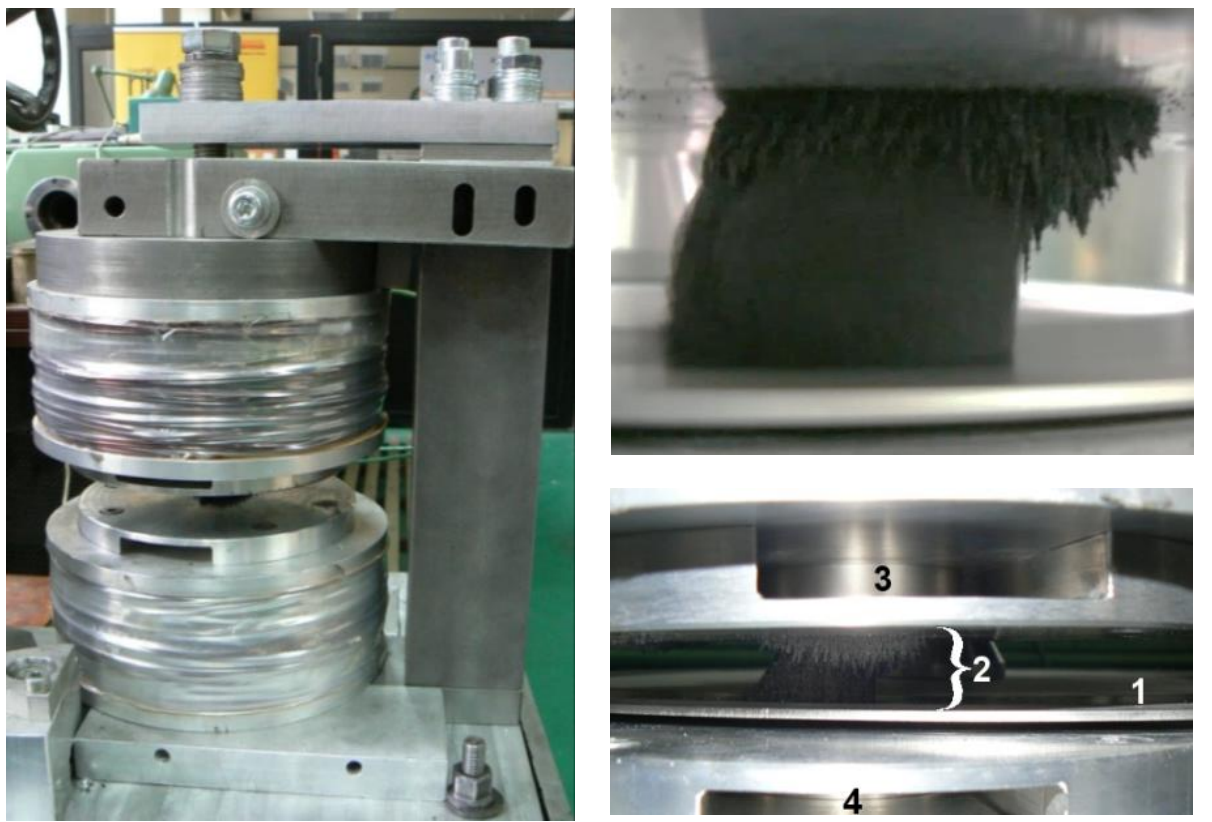

Fig. 2. Experimental station view and flexible tool: 1 - workpiece, 2 - abrasive tool, 3, 4 - permanent magnets

The magnetic field distribution inside the machining gap plays an important role from the abovementioned properties. It has a major impact on the force acting on the abrasive grains, which translates to process efficiency [10]. The magnetic field distribution itself in the machining gap without filling it with abrasive grains is easy to determine (Fig. 3). However, this measurement is subject to a significant error resulting from the change in the magnetic flux in the circuit [11], of which ferromagnetic abrasive grains are a part of [12]. As a result, this stream is larger than in the previous case (Fig. 4). An additional difficulty is the partial migration of abrasive grains during the process and their reorientation [13].

The migration process itself is dependent on the imbalance of mechanical and magnetic forces. The magnetic force acting on the grain comes from the external source of the magnetic field and from the micro-fields of neighbouring abrasive grains $[14,15]$. The larger the number of seeds is in the immediate vicinity, the higher the value of the force holding the grain. In turn mechanical forces are the result of the processes of grain friction between each other and between the grains and the machined surface. If the friction force is greater than the magnetic force that holds the grain, then the grains migrate. The speed of migration depends on the speed of the additional work movement of the object relative to the tool. It should be noted that the most vulnerable to migration abrasive grains are located on the periphery of the molded tool. On this basis it can be concluded that there is a dependence of the external distance of the element generating the magnetic field from the surface of the workpiece and the number of grains undergoing migration during the process. 


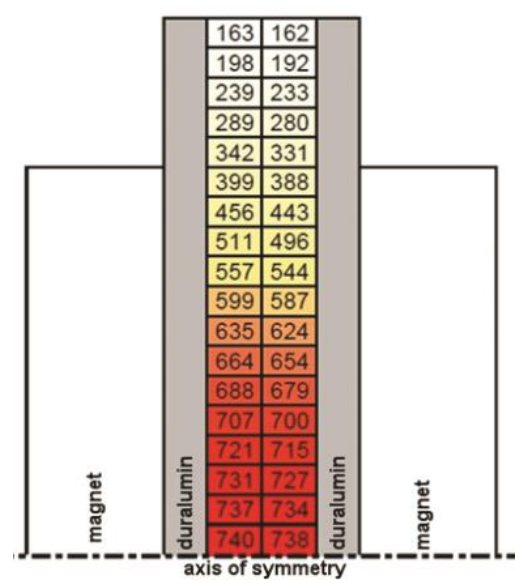

(a)

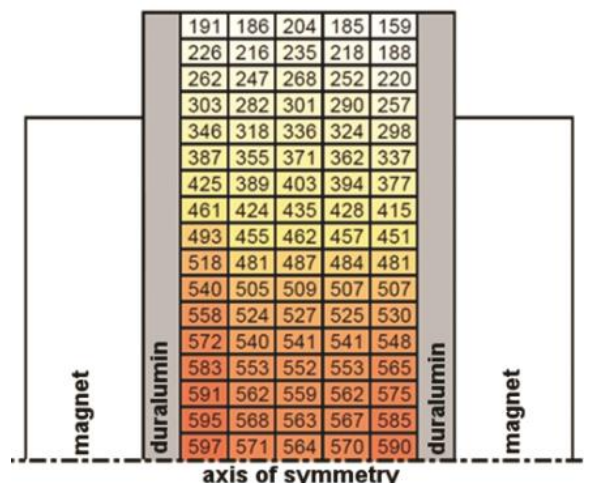

(c)

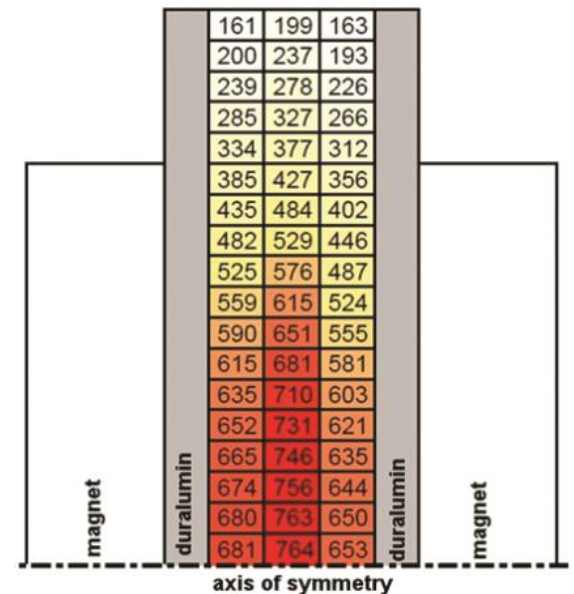

(b)

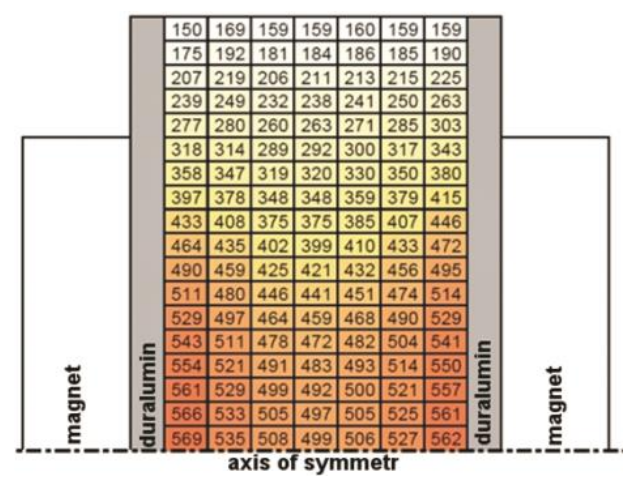

(d)

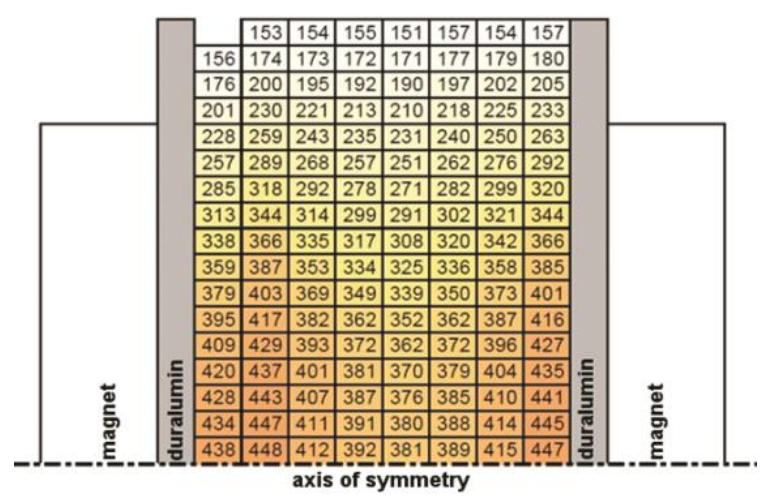

(e)

Fig. 3. Real field distribution of magnetic induction B [x10-3T] in empty gap for distance between magnets: a) $23 \mathrm{~mm}$, b) $28 \mathrm{~mm}, \mathrm{c}) 33 \mathrm{~mm}, \mathrm{~d}) 38 \mathrm{~mm}, \mathrm{e}) 43 \mathrm{~mm}$

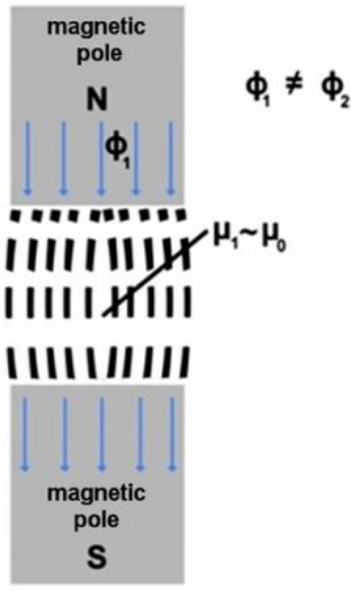

(a)

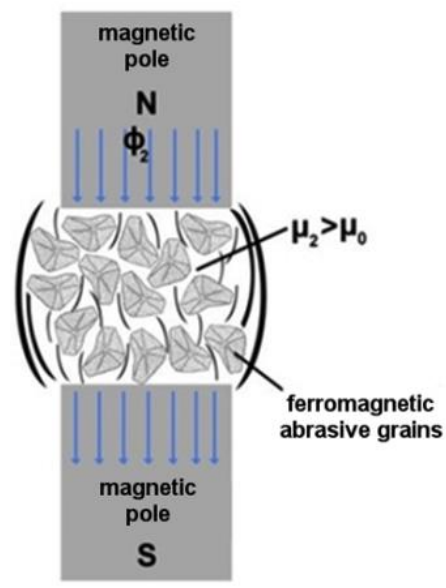

(b)

Fig. 4. Differences in magnetic permeability: a) for air gap, b) gap filled which ferromagnetic abrasive grains 


\section{The concept of determining the actual value of magnetic induction}

In order to determine the actual value of magnetic induction, a station equipped with two sources of electromagnetic force was used (Fig. 5). In the top and bottom heads, between which the working gap is located, two neodymium magnets $(\varnothing 50 \mathrm{~mm} \times 20 \mathrm{~mm})$ are placed in stacks to increase the intensity of the magnetic field.

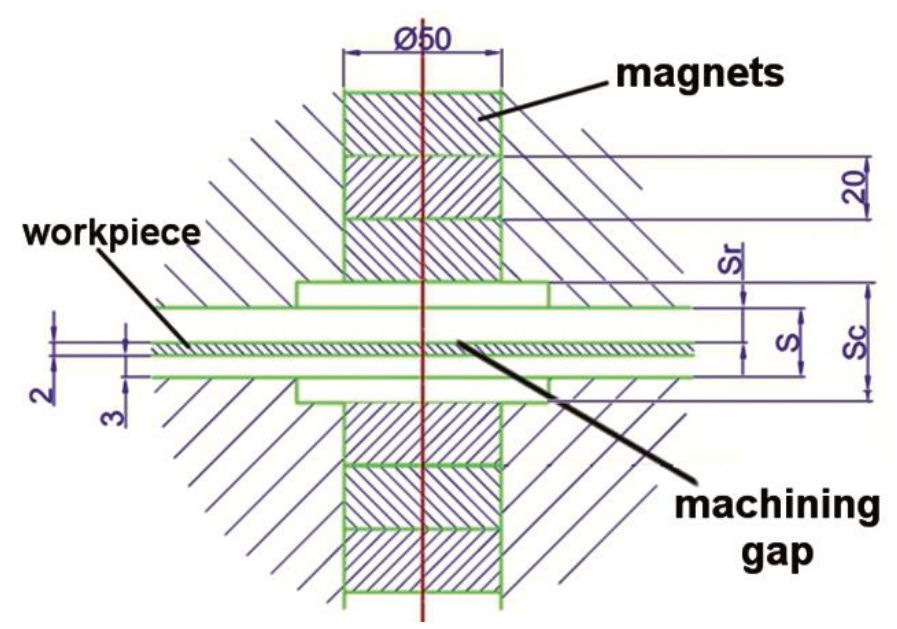

Fig. 5. Sketch of central part of experimental station

The main assumption of the developed concept is to determine the difference in the pulling force of the upper and lower heads at the empty gap and at the gap filled with different amount of abrasive grains. For this purpose, the "volumetric density" of $\mathrm{Fe}-\mathrm{TiC} 315 / 200$ ferromagnetic abrasive grains was determined, and then the grain weight was calculated to fill the working gap by $50 \%$ depending on its width (Table I). Three values of the grain weight were selected, which were then introduced into the gap and the change in deflection of the beam supporting the upper head was recorded (Table II, Fig. 6). The error in measuring the deflection of the beam is $\pm 0.01 \mathrm{~mm}$ (Fig. 7).

The obtained results are presented in the form of a diagram of the change of the attraction force of the upper and lower heads (Table III, Fig. 8). Differences in values are small considering the accuracy of measurement at the level of $\pm 12 \mathrm{~N}$. An additional problem occurs when changing the shape of the abrasive tool depending on the width of the gap and the amount of abrasive grains (Table IV). Grains tend to accumulate in the inner part of the working area with an hourglass shape. At small widths of the machining gap, there is also a process of "jamming" of the grains between them, which causes the heads to abrade with the abrasive tool.

Table I. Gap filling depending from the distance between magnets

\begin{tabular}{ccc}
\hline $\mathbf{S}[\mathbf{m m}]$ & V50 $\left[\mathbf{m m}^{3}\right]$ & M50 [g] \\
\hline 5 & 4908 & 11.8 \\
10 & 9817 & 23.7 \\
15 & 14726 & 35.5 \\
20 & 19634 & 47.4 \\
25 & 24543 & 59.3 \\
30 & 29452 & 71.1 \\
\hline
\end{tabular}

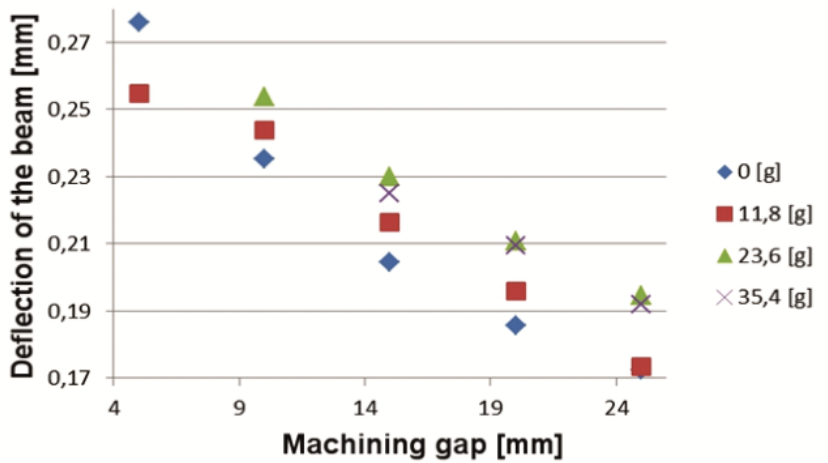

Fig. 6. Deflection arrow of upper head beam for different gap distance 
Table II. Measuring results of beam deflection [mm]

\begin{tabular}{ccccc}
\hline \multirow{2}{*}{ Gap [mm] } & \multicolumn{5}{c}{ Mass [g] } \\
\cline { 2 - 5 } & $\mathbf{0}$ & $\mathbf{1 1 . 8}$ & $\mathbf{2 3 . 7}$ & $\mathbf{3 5 . 5}$ \\
\hline 5 & 0.28 & 0.25 & & \\
10 & 0.24 & 0.24 & 0.25 & 0.23 \\
15 & 0.20 & 0.22 & 0.23 & 0.21 \\
20 & 0.19 & 0.20 & 0.21 & 0.19 \\
25 & 0.17 & 0.17 & 0.19 & \\
\hline
\end{tabular}

Table III. Force F $[\mathrm{N}]$ of attraction of upper and lower head

\begin{tabular}{ccccc}
\hline \multirow{2}{*}{ Gap [mm] } & \multicolumn{5}{c}{ Mass [g] } \\
\cline { 2 - 5 } & $\mathbf{0}$ & $\mathbf{1 1 . 8}$ & $\mathbf{2 3 . 7}$ & $\mathbf{3 5 . 5}$ \\
\hline 5 & 386.88 & 355.94 & 322.80 & 290.22 \\
10 & 336.00 & 342.40 & 295.74 & 272.54 \\
15 & 296.99 & 308.05 & 273.93 & 252.01 \\
20 & 254.74 & 282.24 & 255.06 & \\
25 & 238.66 & 253.44 & & \\
\hline
\end{tabular}

Table IV. Abrasive tool view depending from gap size and abrasive grains mass

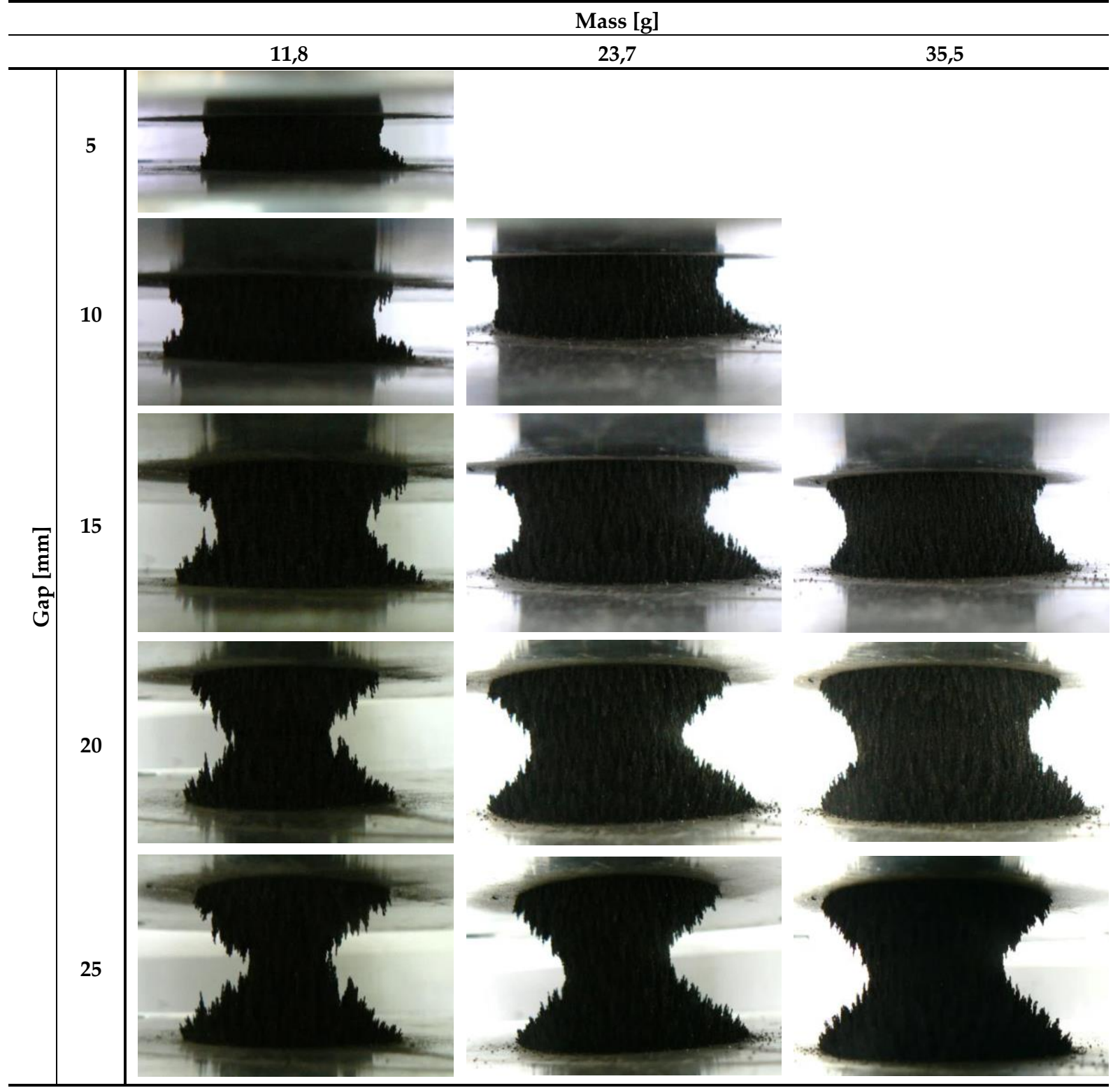




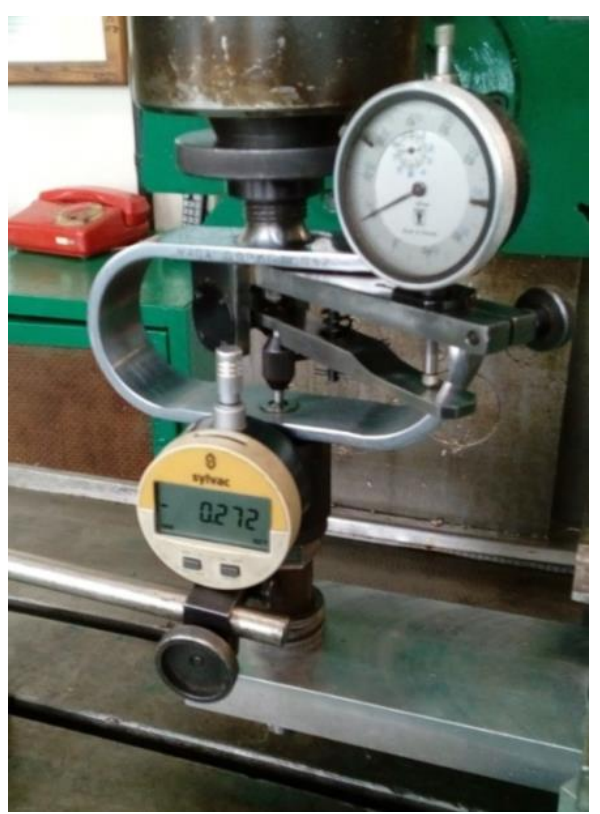

Fig. 7. Deflection beam calibration using dynamometer

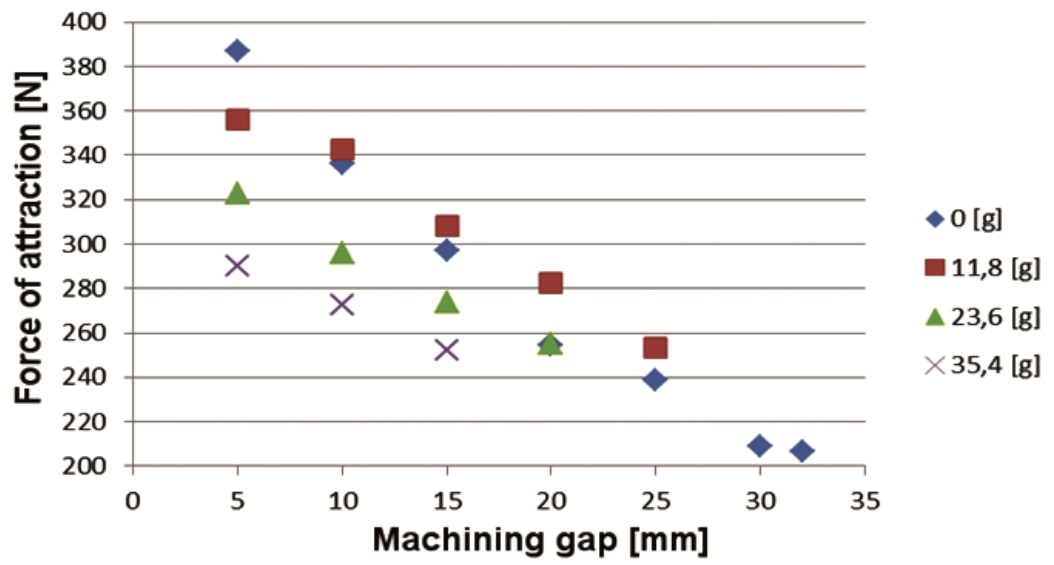

Fig. 8. Force of attraction upper and lower head depending on the gap distance and abrasive grains mass

\section{Conclusions}

There is a big problem with determining the actual distribution of magnetic induction inside the machining gap filled with abrasive material on the magnetic substrate. The prepared station is adapted to transfer large forces through the upper head, which prevents precise registration of the beam deflection measurements within the assumed range. The force acting on the beam may be dependent on the shape of the abrasive tool being formed. Too high concentration of grains in the gap results in the upper head clinging to the abrasive in a static state. This problem during machining occurs to a much lesser extent due to the migration of abrasive grains due to the occurrence of friction and centrifugal forces. In order to carry out measurements with greater accuracy, tests must be carried out during machining.

The method used to determine the magnetic induction is an indirect method, which makes it sensitive to errors in individual stages. At the same time, it depends on the shape of the abrasive tool formed during the process. However, its unquestionable advantage is to determine the real conditions prevailing inside the machining gap.

Conflicts of Interest: The authors declare no conflict of interest.

\section{References}

[1] Marczak M., Magnetic polishing of butt welded pipes. Weldig Technology Review, 2016, Vol. 88(3), 38-40. [CrossRef]

[2] Naveen K., Shanbhag V.V., Balashanmugam N., Vinod P., Ultra-precision Finishing by Magnetic Abrasive Finishing Process. Material today: proceedings 2018, Vol. 5, 12426-12436. [CrossRef] 
[3] Singh R.K., Singh D.K., Gangwar S., Advances in Magnetic Abrasive Finishing of Futuristic Reguirements - A review. Materials today: proceedings, 2018, Vol. 5(9), 20455-20463. [CrossRef]

[4] He B., Wei C., Ding S., Shi Z., A survey of methods for detecting metallic grinding burn. Measurement, 2019, Vol. 134, 426-439. [CrossRef]

Strivastava A., Kumar H., Singh S., Investigation into Internal Surface Finishing of Titanium (Grade 2) Pipe with Extended Magnetic Tool. Procedia Manufacturing, 2018, Vol. 26, 181-189. [CrossRef]

[5] Karakurt I., Ho K.Y., Ledford C., Gamzina D., Horn T., Luhmann N.C., Lin L., Development of a magnetically driven abrasive polishing process for additively manufactured copper structures. Procedia Manufacturing, 2018, Vol. 26, 798-805. [CrossRef]

[6] Alam Z., Jha S., Reprint of "Modeling of surface roughness in ball end magnetorheological finishing (BEMRF) process". Wear, 2017, 376-377. [CrossRef]

[7] Yuewu G., Yugang Z., Guiguan Z., Preparation of Al2O3 magnetic abrasives by gas-solid two-phase double-stage atomization and rapid solidification. Materials Letters, 2018, Vol. 215, 300-304. [CrossRef]

[8] Zimmerman J., Golański D., Chmielewski T., Włosiński W., Calculation model for analysis of residual stresses in the coating-substrate system during deposition by thermal spraying methods. Welding Technology Review, 2013, Vol. 85(1), 12-16. [CrossRef]

[9] Zhang J., Hu J., Wang H., Kumar A.S., Chaudhari A., A novel magnetically driven polishing technique for internal surface finishing. Precision Engineering, 2018, Vol. 54, 222-232. [CrossRef]

[10] Roskosz M., Fryczowski K., Majcherczyk M., Kuśmider P., Studies of the impact of magnetic conditions during loading process on residual magnetic field in ferritic samples. Welding Technology Review, 2014, Vol. 86(10), 45-50. [CrossRef]

[11] Sun X., Huang J., Yang J., Chen S., Microstructure evolution and mechanical properties of in-situ bimodal TiC-Fe coatings prepared by reactive plasma spraying. Ceramics International, 2019, Vol. 45(5), 5848-5857. [CrossRef]

[12] Jiang G., Hing A.K., Chen-Nan S., Hao G.M., Wai K.C., Kui L., Jun W., Suzuki H., Renke K., Novel rotatingvibrating magnetic abrasive polishing method for double-layered internal surface finishing. Journal of Materials Processing Technology, 2019, Vol. 264, 422-437. [CrossRef]

[13] Pei-Ying W., Hitomi Y., Material removal mechanism of additively manufactured components finished using magnetic abrasive finishing. Procedia Manufacturing, 2018, Vol.26, 394-402. [CrossRef]

[14] Sidara A., Jain V.K., Analysis of force on the freeform surface in magnetorheological fluid based finishing process. International Journal of Machine Tools \& Manufactured, 2013, Vol. 69, 1-10. [CrossRef]

(C) 2019 by the authors. Submitted for possible open access publication under the terms and conditions of the Creative Commons Attribution (CC BY) license (http://creativecommons.org/licenses/by/4.0/). 